\title{
Variations in the Cross-Sectional Shape of the Apical Thirds of the Root Canals in Maxillary and Mandibular Teeth
}

\author{
Rizky Putri Arfianti1@, Dewa Ayu Nyoman Putri Artiningsih²®, Kamizar Nazar²®
}

${ }^{1}$ Undergraduate Program, Faculty of Dentistry, Universitas Indonesia, Jakarta, Indonesia.

${ }^{2}$ Department of Conservative Dentistry, Faculty of Dentistry, Universitas Indonesia, Jakarta, Indonesia.

Author to whom correspondence should be addressed: Kamizar Nazar, Department of Conservative Dentistry, Faculty of Dentistry, Universitas Indonesia. Jl. Salemba Raya No. 4 Jakarta 13410, Indonesia. Phone: +62 213913413. E-mail: kamizar_kz@yahoo.com.

Academic Editor: Alessandro Leite Cavalcanti

Received: 18 February 2020 / Accepted: 30 June 2020 / Published: 21 July 2020

How to cite this article: Arfianti RP, Artiningsih DANP, Nazar K. Variations in the cross-sectional shape of the apical thirds of the root canals in maxillary and mandibular teeth. Pesqui Bras Odontopediatria Clín Integr. 2020; 20 :e5696. https://doi.org/10.1590/pboci.2020.142

\begin{abstract}
Objective: To determine the prevalence of cross-sectional variations in the apical thirds of the root canals in maxillary and mandibular teeth. Material and Methods: Eighty tooth samples (maxillary second premolar, maxillary first molar, and mandibular first molar) were scanned using micro-computed tomography. The apical third area of each root canal was sectioned and the maximum and minimum diameters were calculated from the mesiodistal and buccolingual diameters. The shapes were categorized as a round, oval, long oval, and flat based on the ratios obtained. Results: The most common shape of the apical third of the root canals in the maxillary second premolars was oval (66.7\%), followed by long oval (24.6\%), flat (7\%), and round (1.7\%). The corresponding values in the mesiobuccal root of the maxillary first molars were oval (68.2\%), long oval (22.7\%), flat (9.1\%), $94.1 \%$ of the distobuccal roots were oval, while the remaining were long oval $(5.9 \%)$. All the palatal root canals were oval. In the mesiobuccal root of the mandibular first molars, $47.4 \%$ were long oval in shape, followed by $36.8 \%$ oval and $15.8 \%$ flat canals. All the mesiolingual root canals were oval, whereas, in the distal root, $68.4 \%$ were oval, $21.1 \%$ long oval, and $10.5 \%$ were flat. Conclusion: The oval shape was most commonly observed in the majority of the root canals. Knowledge about the apical anatomy of the root can help the operator improve the root canal treatment's success.
\end{abstract}

Keywords: Endodontics; Dental Pulp Cavity; Anatomy, Cross-Sectional; Molar; Bicuspid. 


\section{Introduction}

Canal preparation is one of the most important steps in root canal treatment [1]. The aim of root canal preparation is to remove the organic and inorganic tissues remaining in the canal and to shape it to achieve a hermetic and three-dimensional filling [2,3]. During the root canal cleaning process, the instrument must contact and reach all the walls of the canal [Q]

The apical area of the root canal is a critical zone during instrumentation; thus, the canal's cleaning and shaping have proven to be a challenge in endodontic treatment [4]. In approximately $35 \%$ to $58 \%$ cases, the apical third of root canals have been inadequately prepared due to the shape of the canals [5]. Bacteria have been shown to remain in the non-instrumented areas of the apical part of the root after one-visit treatments [6].

The prevalence of oval-shaped canals is greater than 50\% in the maxillary second premolars [7]. At a distance of 3-5 mm from the apex, the shape of the root was reported to be oval in about $50 \%$ of the maxillary first molars and $59 \%$ of the mandibular first molars; about $69.93 \%$ of the mandibular first molars presented with oval-shaped canals [8]. Variations in cross-sections from the apical third of the teeth (round, oval, long oval, and flat) have been reported [9].

In the present study, we evaluated the prevalence of cross-sectional variations in the canal's shape in the apical third of maxillary second premolar, maxillary first molar, and mandibular first molars.

\section{Material and Methods}

Tooth Selection

Maxillary second premolars, maxillary first molars, and mandibular first molars were used in this study. The selection criteria were posterior teeth (maxillary second premolar, maxillary first molars, and mandibular first molar), complete root development and apex closure, no damage/defect in the root of the tooth, and no history of dental treatment for the teeth. A total of 80 teeth comprising 44 maxillary premolars with 57 root canals, 17 maxillary first molars with 56 root canals, and 19 mandibular first molars with 43 root canals were included. The teeth were immersed in $\mathrm{NaCl}$ solution to remove the calculus and debris.

This study used the convenience sampling technique. The shape of the root canal was assessed using micro-computed tomography. A reference point within 2.5 and $3.5 \mathrm{~mm}$ from the apical end was taken.

The shape was analyzed by measuring the maximum and minimum diameters as described by some authors that proposed various methods to calculate the maximum working width in the buccolingual and mesiodistal direction [10]. The longest diameter in the buccolingual direction was defined as the maximum diameter, whereas the longest diameter in the mesiodistal direction was defined as the minimum diameter (Figure 1). Based on the ratio of the maximum diameter to the minimum diameter, the shape of the canal was classified as round (1), oval $(>1-\leq 2)$, long oval $(>2-\leq 4)$, and flat $(>4)[9]$.

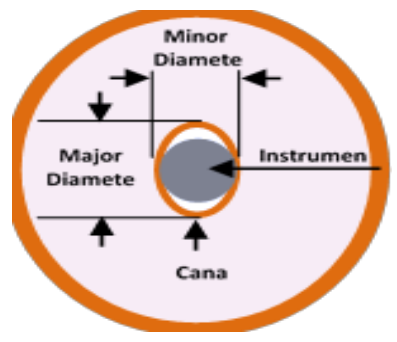

Figure 1. The working width, as seen from a cross-section of the apical root canal. 


\section{Micro-Computed Tomography Analysis}

All teeth were scanned using a SkyScan 1173 Micro-CT (Bruker Corporation Billerica, MA, USA) at the following settings: resolution, $50 \mu \mathrm{m}$ (medium); pixel size, 71.25 microns; voltage, $130 \mathrm{kV}$; current, $60 \mu \mathrm{A}$; rotation angle, $240^{\circ}$; and time exposure, $295 \mathrm{~ms}$. Image reconstruction was analyzed using the NRecon and NRecon Server software. The reconstruction visualization process was analyzed using the DataViewer software to observe the cross-section of the root canal. Root canal diameter was analyzed using the Fiji ImageJ software.

\section{Data Analysis}

Data were analyzed using IBM SPSS Statistics for Windows Software, version 20 (IBM Corp., Armonk, NY, USA). Descriptive statistics were used to calculate the relative frequencies.

\section{Results}

As shown in Table 1, the prevalence of the various shapes of the canals in the apical third crosssections of the root canals in the maxillary second premolar was as follows: oval (66.7\%), long oval (24.6\%), flat $(7 \%)$, and round (1.7\%). In corresponding numbers in the maxillary first molars were as follows: oval (68.2\%), long oval (22.7\%), and flat (9.1\%) in the mesiobuccal (MB) root canal; oval (94.1\%) and long oval (5.9\%) in the distobuccal (DB) canal; and oval (100\%) in the palatal (P) canal. In mandibular first molars, the prevalence of the shape of the canal in the apical third was long oval $(47.4 \%)$, oval $(36.8 \%)$, and flat (15.8 \%) in the MB canal, oval $(100 \%)$ in the mesiolingual (ML) canal, and oval (68.4\%), long oval (21.1\%), and flat (10.5\%) in the distal (D) canal (Table 1).

Table 1. The variations in the shape of the root canal at the apical third of the maxillary second premolars, maxillary first molars, and mandibular first molars.

\begin{tabular}{|c|c|c|c|c|c|}
\hline Teeth & & Round & Oval & Long Oval & Flat \\
\hline Maxillary $2^{\text {nd }}$ Premolars & & $1.7 \%$ & $66.7 \%$ & $24.6 \%$ & $7 \%$ \\
\hline \multirow[t]{3}{*}{ Maxillary $1^{\text {st }}$ Molars } & MB & - & $68.2 \%$ & $22.7 \%$ & $9.1 \%$ \\
\hline & $\mathrm{DB}$ & - & $94.1 \%$ & $5.9 \%$ & - \\
\hline & $\mathrm{P}$ & - & $100.0 \%$ & - & - \\
\hline \multirow[t]{3}{*}{ Mandibular $1^{\text {st }}$ Molars } & MB & - & $36.8 \%$ & $47.4 \%$ & $15.8 \%$ \\
\hline & ML & - & $100.0 \%$ & - & - \\
\hline & $\mathrm{D}$ & - & $68.4 \%$ & $21.1 \%$ & $10.5 \%$ \\
\hline
\end{tabular}

MB: Mesiobuccal; DB: Distobuccal; P: Palatal; ML: Mesiolingual.

The most common shape in the apical third of the maxillary second premolars was oval (66.7\%), followed by long oval (24.6\%). The cross-section of the root canals of the maxillary second premolars was varied. The most prevalence shape of the entire apical third in the MB, DB, and Palatal roots of the maxillary first molars was ovals followed by long oval and flat; the oval shape was most prevalent in the Palatal root canal, whereas the long oval shape was most prevalent in, the MB root canal. Increased variations in the shapes of the cross-sections were noted in the MB root canal.

The most common shape of the canal in the mandibular first molars was long oval in the MD root canal, whereas, in the ML and D root canals, the most prevalent shape was oval. The cross-sections of the MB and $\mathrm{D}$ roots demonstrated variations in shape.

\section{Discussion}


This study used samples obtained from maxillary second premolars, maxillary first molars, and mandibular first molars. In a previous study, more than $50 \%$ of the maxillary second premolars had an ovalshaped root canal in the apical third [7]. Other authors also reported that the oval shape was most common $(69.93 \%)$ in the mandibular first molars [8].

A reference point within $2.5 \mathrm{~mm}$ and $3.5 \mathrm{~mm}$ from the apical end was used in this study, based on the argument that the two points were in the apical third and approaching apical constriction. The apical constriction is located $0.5-1.0 \mathrm{~mm}$ from the apical foramen, while the apical foramen is located $0.5-1.0 \mathrm{~mm}$ from the anatomical apex [11]. The micro-CT device is considered as the most appropriate device to obtain a $3 \mathrm{D}$ view of the root canal cross-section because it is non-destructive [12], can evaluate the tooth anatomy [13], and show a detailed/clear view of the morphology of the root canal and apical area [14]. This method was previously used to illustrate the $3 \mathrm{D}$ cross-section $\mathrm{f}$ the root canal at each level [14].

In the current study, the shapes of the root canals in the apical thirds of the maxillary second premolars were diverse. The prevalence of the oval shape in this study (66.7\%) was similar to that reported by other authors using a microscope at a magnification of $30 \times$. However, the shape of the root canal at the apical third of the maxillary second premolars is generally round [15]. The prevalence of a round-shaped canal in the present study was only $1.8 \%$.

In the maxillary first molars, the oval shape was the most common shape found in the MB root canal. This is not in accordance with previous authors' findings, who reported that the apical third of the MB root canal is generally round in shape [15]. Likewise, the most dominant shape in the DB root canal was the oval shape $(94.1 \%)$, followed by the long oval shape (5.9\%). The DB roots are generally round or oval [16]. All the Palatal root canals in the current study were oval, contrary to previously reported, that showed that the Palatal root canal is generally round in shape in the apical third [15]. Overall, oval was the most dominant shape in the apical third of the maxillary first molar root canal. This finding is in accordance with the literature [8]; however, these authors did not examine each root canals of the mandibular first molars.

In the mandibular first molars, the cross-sectional shape of the apical third of the root canal was quite diverse in the current study. Oval, long oval, and flat root canals were observed in the MB root with long oval being the most common (47.4\%), followed by oval (36.8\%), and flat (15.8\%). In the ML root canal, all the root canals were oval, whereas in the D root canal, the most dominant shape was oval (68.4\%), followed by long oval $(21.1 \%)$ and flat $(10.5 \%)$. According to Ingle, the distal root is generally oval [16]. The most dominant shape in the apical third of the mandibular first molar root canal was oval, which is in accordance with previous findings $[8,9]$. Contrary to the previously published studies, each root canal's cross-sectional shape was analyzed to obtain specific results. Additionally, this study used micro-CT devices to observe the anatomy of the root canal.

Variations between results of this study compared to other studies [8,17], may be attributed to the calculation methods used to determine the shape of the root canal. Furthermore, different measuring instruments such as stereomicroscopes led to the loss of anatomical structure while cutting the dental samples [18] and CBCT, which resulted in blur/scattering [19], were used in the previous studies.

Knowledge of the apical anatomy is important to increase the success of the root canal treatment. The infected root canal must be thoroughly disinfected because the microorganisms located in the apical part have access to the periapical tissue and can endanger the surrounding structure. When cleaning the root canals, the instrument must contact and reach all the root canal walls to remove the debris and bacteria [2]. It is 
important to evaluate and modify the technique to ensure adequate cleaning of the root canal and foramen closure, particularly in non-round root canals.

In the current study, only the apical third of the root canal was assessed. Further studies evaluating the cross-sectional shape of the canal from the cervical end to the apex are merited. Additionally, the remaining types of teeth in the oral cavity, other than maxillary premolar, maxillary first molar, and mandibular first molar, must be examined using micro-CT.

\section{Conclusion}

The oval shape was the most dominant in the root canal cross-sections in the apical thirds of the maxillary second premolar, maxillary first molar, and mandibular first molar in this study. Currently, most instruments are round and should ideally be used to clean and prepare root canals that are round in shape. Thus, it is important to evaluate the root and modify the technique or instrument accordingly, to ensure adequate cleaning of the root canal.

\section{Authors' Contributions}

$\begin{array}{lll}\text { RPA } & \text { (D) 0000-0001-5956-1724 } & \text { Investigation, Formal Analysis and Writing - Original Draft Preparation. } \\ \text { DAPA } & \text { (D) 0000-0001-7200-3540 } & \text { Writing-Original Draft Preparation and Writing - Review and Editing. } \\ \text { KN } & \text { (D) 0000-000 1-9048-2872 } & \text { Conceptualization, Methodology, Writing - Original Draft Preparation and } \\ \text { Writing - Review and Editing. }\end{array}$
$\begin{aligned} & \text { All authors declare that they contributed to critical review of intellectual content and approval of the final version to be } \\ & \text { published. }\end{aligned}$

\section{Financial Support}

Directorate Research and Community Engagement Universitas Indonesia Through the International Workshop on Dental Research Grant 2019 (Grant Number: IWDR 4/2019).

\section{Conflict of Interest}

The authors declare no conflicts of interest.

\section{References}

[1] Spångberg, L. The wonderful world of rotary root canal preparation. Oral Surg Oral Med Oral Pathol 2001; 92(5):479. https://doi.org/10.1067/moe.2001.120438

[2] Torabinejad M, Walton RE. Principles and Practice of Endodontics. 3rd ed. London: W. B. Saunders Company; 2002.

[3] Moradi S, Talati A, Zadeh AM. Centering ability and dentin removal of rotary systems in curved root canals. Iran Endod J 2009; 4(3):91-5. https://doi.org/10.22037/iej.v4i3.1416

[4] Young GR, Parashos P, Messer HH. The principles of techniques for cleaning root canals. Aust Dent J 2007; 52(1 Suppl):S52-63. https://doi.org/10.1111/j.1834-7819.2007.tbo0526.x

[5] Cachapuz JR, Sassone LM, Fidel RAS, Vilhena FS. Histological evaluation of refinement influence in the cleaning efficacy of rotary nickel-titanium ProTaper ${ }^{\circledR}$ instruments in oval-shaped root canals. RSBO 2013; 10(1):24-8.

[6] Alothmani OS, Chandler NP, Friedlander LT. The anatomy of the root apex: a review and clinical considerations in endodontics. Saudi Endod J 2013; 3(1):1-9. https://doi.org/10.4103/1658-5984.116273

[7] Mohammadi Z, Shalavi S, Jafarzadeh H. The oval shaped root canal: a clinical review. S Afr Dent J 2015; 70(5):200-4.

[8] Abarca J, Zaror C, Monardes H, Hermosilla V, Muñoz C, Cantin M. Morphology of the physiological apical foramen in maxillary and mandibular first molars. Int J Morphol 2015; 32(2):671-7. https://doi.org/10.4067/S071795022014000200048

[9] Tikku AP, Pandey WP, Shukla I. Intricate internal anatomy of teeth and its clinical significance in endodontics - a review. Endodontology 2012; 24(2):160-9. 
[10] Eid GEH, Amin SAW. Changes in diameter, cross-sectional area, and extent of canal-wall touching on using 3 instrumentation techniques in long-oval canals. Oral Surg Oral Med Oral Pathol Oral Radiol Endod 2011; 112(5):688-95. https://doi.org/10.1016/j.tripleo.2011.05.007

[11] Chaudhari A, Asthana G, Parmar G, Vadher R, Kaur M. Significant of apical third a review. Sch J App Med Sci 2014; 2(5B):1613-7.

[12] Jyothi P, Kamishetty S, Reddy S, Chandra R. Micro computed tomography - potential research and diagnostic tool in dentistry. Arch Dent Med Res 2016; 2(3):43-9.

[13] Gao Y, Peters OA, Wu H, Zhou X. An application framework of three-dimensional reconstruction and measurement for endodontic research. J Endod 2009; 35(2):269-74. https://doi.org/10.1016/j.joen.2008.11.011

[14] Craciunescu EL, Boariu M, Ionitta C, Pop DM, Sinescu C, Romînu M, et al. Micro-CT and optical microscopy imagistic investigations of root canal morphology. Rom J Morphol Embryol 2016; 57(3):1069-73.

[15] Garg, N, Garg A. Textbook of Endodontics. 3rd ed. New Delhi: Jaypee Brothers Medical Publishers; 2014.

[16] Ingle JI, Bakland LK, Baumgartner JC. Ingle's Endodontics 6th ed. Maidenhead: McGraw-Hill Education; 2008.

[17] Lu T, Yang S, Pai S. Complicated root canal morphology of mandibular first premolar in a Chinese population using the cross section method. J Endod 2006; 32(10):932-6. https://doi.org/10.1016/j.joen.2006.04.008

[18] Sanjai K, Kumarswamy J, Patil A, Papaiah L, Jayaram S, Krishnan L. Evaluation and comparison of decalcification agents on the human teeth. J Oral Maxillofac Pathol 2012; 16(2):222-7. https://doi.org/10.4103/0973-029X.99070

[19] Marca C, Dummer PMH, Bryant S, Vier-pelisser FV, Só MVR, Fontanella V, et al. Three-rooted premolar analyzed by high-resolution and cone beam CT. Clin Oral Investig 2013; 17(6):1535-40.

https://doi.org/10.1007/s00784-012-0839-5 